\title{
COMPARECENCIA DE FRANCISCO RUBIO LLORENTE ANTE LA PONENCIA DE AUTOGOBIERNO DEL PARLAMENTO VASCO (1.10.2014)
}

\section{HEARING OF FRANCISCO RUBIO LLORENTE AT THE WORKGROUP OF SELF- GOVERNMENT OF THE BASQUE PARLIAMENT (2014.10.01)}

\section{Francisco Rubio Llorente}

Francisco Caamaño Domínguez

Universidade da Coruña

Cómo citar / Nola aipatu: Rubio Llorente, F. y Caamaño Domínguez, F. (2021).

Comparecencia de Francisco Rubio Llorente ante la Ponencia de Autogobierno del Parlamento Vasco (1.10.2014).

Legebiltzarreko Aldizkaria - LEGAL - Revista del Parlamento Vasco, 2: 228-261

https://doi.org/10.47984/legal.2021.009

\section{LOS DEMÁS, SON LA DEMOCRACIA: NOTA INTRODUCTORIA}

Agradezco al Parlamento Vasco la publicación de la comparecencia llevada a cabo por mi admirado maestro Francisco Rubio Llorente el día 1 de octubre de 2014, ante la Ponencia de Autogobierno, así como la invitación para escribir este breve apunte introductorio.

Al leer la transcripción he vuelto a escucharlo. Su voz, debilitada por los años, contrasta con la juventud, la fuerza y la valentía de sus palabras. Allí, adonde le llevó su inteligencia, callarse nunca fue una alternativa. La honestidad de la razón era parte inherente de su compromiso con los demás, con lo público, aunque a veces fuese por ello incomprendido.

Me gusta la forma de pensar del último Rubio. No solo porque me siento reflejado en muchas de sus ideas, singularmente las relacionadas con una visión de España que algunos consideraron poco afortunadas, en razón del momento político en que las defendió. También, sobre todo, por la claridad de fondo de un jurista, capaz de ser 
el primer crítico de sí mismo y de mantener ese punto iconoclasta tan necesario para provocar el debate y apuntar, en situaciones difíciles, soluciones que puedan mejorar las cosas. Volcado en construir una España verdaderamente constitucional y democrática, no podía ocultar su preocupación por los problemas persistentes y no resueltos, ni dejar de preguntarse cómo corregir una genética del pasado que condicionaba en exceso el presente y amenazaba con oscurecer el futuro.

Como otros muchos constitucionalistas hemos defendido la necesidad de acometer una reforma de la Constitución, aun conscientes de su imposibilidad. De tener que romper el bucle y habilitar un cauce imaginativo mediante el que lograr modificar el procedimiento de reforma. Sería la modificación de la primera Constitución española que ha tenido la fortaleza de escribir su propia historia. La primera lo suficientemente vivida como para conocer sus debilidades y sus fortalezas. Leer el informe sobre la reforma constitucional ${ }^{1}$ que elaboró el Consejo de Estado de la mano de Francisco Rubio, es recuperar la confianza en una España serena y demasiado ausente.

Más solos nos quedamos los dos a la hora de cuestionar, en una democracia asentada, la utilidad del recurso de inconstitucionalidad o de mantener el carácter constructivo de la moción de censura. Lo mismo podría decir al argumentar la conveniencia de permitir, con condiciones, referendos autonómicos; expresar nuestra disconformidad con la atribución de competencias al Tribunal Constitucional para obligar a cumplir sus pronunciamientos o repensar algunos aspectos del estado autonómico, sin desconocer su pluralidad nacional.

Reconozco que nuestra mirada, aunque apuntase hacia un mismo horizonte, no siempre coincidía, ni resultaba fácil de encajar. Rubio me perdonaba y, a veces, hasta se divertía con las distorsiones de mi hipermetropía.

En la comparecencia que a continuación podrán leer, a pesar de ciertas lagunas insubsanables debidas a problemas técnicos surgidos durante la grabación, aparecen la mayoría de esas cuestiones. No puedo pararme en todas, ni hacerles comprender lo mucho de Rubio que hay detrás de cada una de ellas. Desde el recurso a su condición de

1 Consejo de Estado. Informe sobre modificaciones de la Constitución Española (febrero, 2006). 
extremeño para explicar la complejidad sentimental de las identidades que configuran España, hasta la habilidad intelectual para toma una frase de Jean Jaurès ("la nación es un espacio de solidaridad") y convertirla, mediante una suerte de "inocente" complemento, en una herramienta útil para el constitucionalismo: "un espacio de solidaridad colectiva" -dice Rubio- "no solo en el sentido figurado de la palabra, sino también en el sentido real... en un territorio determinado. El territorio es, a mi juicio, un componente necesario del concepto de nación".

Ese proceso de construcción y territorialización de solidaridades colectivas es, en mi opinión, lo que a Rubio más le atraía de la caracterización de España como "nación de naciones", aún siendo plenamente consciente de la inestabilidad y de la alta dosis de edulcorante que hay en esa fórmula compuesta. Cuando Julián Marías la oyó, por primera vez, a raíz de una intervención parlamentaria del entonces diputado Gregorio PecesBarba, dijo de ella que era un "ponderativo hebraico", como "el cantar de los cantares".

Permítanme detenerme brevemente en esa parte de su intervención, cuya finalidad comparto, aunque de otra manera.

La inestabilidad de una "nación de naciones" no nace de la nación, ni del territorio, sino de un ingrediente exógeno que los sazona: la soberanía. La existencia de una nación de naciones no plantea problemas hasta el momento en que alguien levanta la mano y pregunta cuál, de todas ellas, es la soberana.

Fiel a su origen monárquico, la soberanía es un concepto que comporta verticalidad, jerarquía, y que tiene en la diferenciación su marca de dominio. Sin embargo, la democracia produce horizontalidad e inclusión. El poder reside en cada individuo por igual y se manifiesta colectivamente a través del derecho de sufragio. Se comprende así por qué allí donde el constitucionalismo fue guiado por la idea del gobierno del pueblo, y no por la consolidación del parlamento en su lucha contra el rey, la soberanía se convirtió en un componente menor, hasta el punto de facilitar la creación de una nueva forma de articular el Estado o, si se prefiere, de vertebrar jurídicamente una diversidad de espacios de solidaridad con proyecciones simultáneas sobre una unidad de territorios diferenciados: el federalismo.

Si en una persona pueden convivir una solidaridad local y otra federal, sin necesidad de exclusiones ni renuncias, ello se debe a que la soberanía se diluye en el interior 
de cada individuo. Ni del Estado, ni de la nación; en democracia solo hay personas soberanas que deciden sus preferencias ejerciendo su voto.

La imagen de la nación de naciones conduce a lo que mi otro maestro, Ramón Máiz, ha denominado "un concepto no nacionalista de nación", es decir "la nación entendida como una comunidad plural, integrada por mayorías y minorías culturales, como un ámbito de diversidad específica, pero asimismo de convivencia y deliberación, donde los derechos de las mayorías no conculquen los derechos de las minorías, donde las protecciones externas de la propia diferencia no "normalicen" el interior en busca de una homogeneidad étnico-cultural. Y en este sentido no nacionalista -de comunidad político-cultural pluralista-, la nación aporta una dimensión identitaria no solo compatible sino estrictamente indispensable para el diseño de una democracia compleja, de una democracia federal".

Un poco cansado de la interminable contienda sobre la nación y la soberanía, desde hace un tiempo he preferido desinflamar las palabras y trasladar mis preocupaciones constitucionales de la vieja teoría del Estado a la teoría de la democracia, en busca de otros argumentos y, acaso, de otras soluciones. Por eso, he arrinconado las anteriores expresiones y prefiero hablar de un "federalismo de las identidades", que pueda ser útil para España y para Europa.

En todo caso, sus problemas no son muy distintos a los que Francisco Rubio ya planteaba en esta comparecencia. ¿Referendos autonómicos?, ¿cómo conseguir que las CCAA puedan participar en la reforma constitucional?, ¿qué hacer con la asimetría estructural de nuestra constitución y el reconocimiento de los hechos diferenciales?

La reflexión que sigue a cada uno de esos interrogantes es una invitación intelectual a la aventura de pensar sobre nosotros mismos, sobre qué esperamos y qué queremos ser. Tenemos la ruta, con todas sus incertezas. Contamos con las anotaciones de un excelente guía. Nos falta discutir menos y escucharnos más. 


\section{TRANSCRIPCIÓN LITERAL DE LA COMPARECENCIA DE D. FRANCISCO RUBIO LLORENTE}

\section{FRANCISCO RUBIO LLORENTE JAUNAK IZANDAKO AGERRALDIAREN HITZEZ HITZEKO TRANSKRIPZIOA²}

LANTALDEAREN KOORDINATZAILEAK (Berriozabal Bóveda andreak):

Egun on guztioi. Hasiera emango diogu gaurko batzordeari. Dakizuenez, beste baterako utzi da gaurko aurreikusita zegoen lehenengo agerraldia, Kataluniako Parlamentuan ohiko bilkura deitu delako. Horregatik, zuzenean bigarren agerraldiari ekingo diogu.

Tenemos con nosotros a Francisco Rubio Llorente, doctor en Derecho, que también fue letrado mayor de Las Cortes Generales y magistrado en el Tribunal Constitucional. Sin más, le damos la palabra al señor Rubio Llorente.

RUBIO LLORENTE jaunak:

Yo tengo que, en primer lugar, expresar mi agradecimiento por el honor que el Parlamento Vasco me hace invitándome. Me he sentido por ello obligado a hacer el esfuerzo, porque a los 84 años desplazarse, me ha planteado algunos problemas. Ese sentimiento de agradecimiento va acompañado de un sentimiento de cierta preocupación porque tengo la sospecha bien fundada de que la utilidad de mi comparecencia no compensará ni con mucho los gastos que el Parlamento ha hecho para traerme hasta aquí. Pero, en fin, eso ustedes deciden. Bien.

En cuanto a esta intervención inicial, los servicios del Parlamento me indicaron su duración aconsejable o máxima, pero no el tema. Entonces, yo lo que voy a intentar es tratar de darle, en términos muy resumidos, mi opinión sobre la situación actual del estado de las autonomías, las razones que, a mi juicio, aconsejan la reforma constitucional, y las dificultades que esta reforma entraña.

2 Nota del editor: Como se advertirá, la transcripción de la comparecencia del profesor Rubio Llorente presenta algunas lagunas. El motivo de ello es la calidad de la grabación, que en algunos instantes es deficiente y a la hora de transcribir no se puede escuchar con claridad. Sin embargo, el valor del documento, que refleja el pensamiento de este insigne jurista, nos ha hecho considerar que pese a todas las deficiencias técnicas, merece la pena que se ponga a disposición de los lectores y lectoras de nuestra revista. 
La necesidad de corregir los defectos del estado de las autonomías no es la única razón que aconseja la reforma constitucional, hay también otros defectos que corregir, pero yo me referiré exclusivamente a este problema concreto que, supongo que, es el que a ustedes les interesa.

Haré eso y, después, al final, y dentro de ese marco general, intentaré hacer alguna referencia concreta a problemas específicamente vascos, especialmente en el que, a mi juicio, y voy a dar una opinión que seguramente no será compartida, toca al Cupo, al problema del Cupo vasco o de la aportación navarra. Bien.

En todo caso, como mi opinión sobre el presente del estado de las autonomías se fundamenta sobre la concepción general que yo tengo de España, y mi juicio sobre la solución que se adoptó en 1978, para resolver el problema de la diversidad de la unidad, tendré que comenzar por exponer esta condición.

Yo creo en la nación de naciones. No es una idea fácil y todavía ayer, en un artículo muy brillante de El País, de un distinguido historiador mejicano, se decía que "eso de la nación de naciones era como el misterio de la Santísima Trinidad”. Bueno, yo creo que no es así. Creo que tengo algunas razones para pensar que es un concepto que refleja bien la realidad, y a ello voy.

Si se entiende la nación, como Jean Jaurès, como espacio de solidaridad, entonces, la nación es uno más, de un género muy amplio, de espacios de solidaridad. Todas las identidades colectivas son espacios de solidaridad. Las mujeres se sienten más solidarias de las mujeres que de los hombres. Los homosexuales se sienten más solidarios de otros homosexuales entre sí, y los viejos nos sentimos más solidarios de otros viejos. Ahora, cuando me paseo por mi barrio, pues, con todos los viejos que nos encontramos con bastón, que antes no nos saludábamos, ahora nos saludamos y nos sentimos profundamente solidarios. Bien.

Estos espacios de solidaridad de todas las identidades colectivas son espacios de identidad, de solidaridad. Y uno de estos espacios es, a mi juicio, la nación. La nación es un espacio de solidaridad colectiva, producto de la acción a lo largo de la historia de factores diversos: unidad cultural, convivencia en un mismo territorio, muy señaladamente la sujeción a un mismo poder político, etcétera. La sujeción a un mismo poder que la nación, primero era el poder del monarca, por supuesto, y que es un poder que la nación misma termina asumiendo ella directamente a través del principio de solidaridad nacional.

Y la nación es un espacio de solidaridad colectiva, no solo en el sentido figurado de la palabra espacio, sino también en el sentido real. Es un espacio de solidaridad colectiva en un territorio determinado. La nación, el territorio es, a mi juicio, un componente necesario del concepto de nación.

Ahora, dentro de un mismo territorio, caben diversos espacios de solidaridad colectiva, específicamente política. No de género, no de condición social, etcétera, sino específicamente política. Espacio superpuesto de solidaridad política dentro de un 
mismo territorio, diferenciados por el grado de esa solidaridad, por la intensidad de esa solidaridad. Este es un hecho del que todos tenemos experiencias cotidianas: hay una solidaridad de barrio, una solidaridad de vecinos (...). Y en el País Vasco, qué les voy a decir a ustedes, si es el modelo vivo de la solidaridad superpuesta de los territorios históricos y del País Vasco en su conjunto.

Naturalmente, esta superposición de solidaridades se hace imposible si el criterio de la soberanía, de la nación, se pone no en la solidaridad sino en la soberanía. Y esa es una idea que se afirma a partir de la idea jacobina de soberanía como un poder jurídicamente ilimitado, políticamente ilimitado. No un poder ilimitado en la práctica, pues, por supuesto, ningún poder hay ilimitado en la práctica; unos Estados son más soberanos que otros, etcétera. Pero todos los Estados son igualmente soberanos, desde el punto de vista político y jurídico. Es un principio básico de la Organización de las Naciones Unidas, etcétera, etcétera.

Esta concepción jacobina de la soberanía, que se extendió a muchos otros países por influencia francesa y entre otros al nuestro es, a mi juicio, la que llevó al presidente Wilson a rechazar la oferta que al final de la guerra del 14 le hicieron las potencias centrales, de interpretar el punto décimo de los célebres puntos, 14 puntos de Wilson, en el sentido de que la nación podría realizarse también mediante la autonomía dentro de un estado ajeno. Él lo rechazó, y así fueron las cosas. Nos hubiéramos ahorrado muchos dolores en Europa si las cosas hubieran ido de manera distinta.

Pero en fin, se hace de la soberanía criterio de la nación. Pero no solo se hace de la soberanía criterio de la nación, sino se hace de la nación la soberanía entendida, como digo, como un poder política y jurídicamente ilimitado: puede estar limitado en la práctica, pero no jurídica y políticamente. Y esta no es la concepción única de la soberanía, ni siquiera la concepción original, ni siquiera la concepción razonable. Como saben ustedes bien, la idea de soberanía exteriorizada por primera vez por Bodino, Jean Bodin. Y para Bodino, el rey está sujeto a las leyes reigni; es decir, el rey es soberano, pero no puede ir contra la estructura misma del rey ni contra el fundamento mismo de su poder. Por ejemplo, el rey no puede dividir el reino entre sus hijos, etcétera, etcétera.

Bueno, pues yo entiendo que la soberanía, la soberanía nacional, no puede ir contra la estructura misma de la nación. No puede contrariar, a través del ejercicio de la soberanía, la nación no puede violentar su propia naturaleza. Y que, cuando hay, dentro de una nación, hay comunidades nacionales o nacionalidades, o como quieran ustedes llamar, que han mantenido a lo largo de la historia junto con su pertenencia a la nación también una conciencia de nacionalidad propia, de nación propia, la nación soberana -digamos- es el conjunto. Y la nación soberana al determinarse, al autodeterminarse a través del procedimiento constituyente, etcétera, tiene que asentar o realizarse de manera que se preserve o se asegure esta autonomía 
propia de sus componentes. Hasta aquí, una teoría muy general y muy necesaria de matizaciones, pero en fin.

Lo que sucede es que en este tipo de naciones, de los cuales son buen ejemplo -a mi juicio- el Reino Unido y España, hay siempre una nación que es mucho mayor que las demás: en extensión, en población, de poderío económico -que es solvente, no en riqueza pero sí en poderío económico-. Y esta nación, que podemos llamar a estos efectos "dominante", tiende a identificarse con la nación total. Y esto plantea un problema político y jurídico difícil.

En esta estructura, en una estructura de este género, como esta que digo del Reino Unido, la autonomía de los diversos componentes de esa nación de naciones puede buscarse por dos vías: limitando la autonomía a las naciones menores, nacionalidades, no excluyendo de ellas a la nación dominante, o, por el contrario, generalizando la autonomía a todos los componentes de la nación total; Die große Nation, que dirían los alemanes.

En el Reino Unido, cuando se inicia la política de evolución, con lo de evolution acts, que llega a poner en práctica por primera vez -me parece- Tony Blair, se intenta seguir la vía de las autonomías singularizadas: reconocer la autonomía solo de las nacionalidades componentes de la nación. En cambio, en España, de manera muy dubitativa en 1931, y de manera más resuelta en 1978, se opta por la segunda vía, la de la generalización de las autonomías. Una vía que parece, después de los resultados del referéndum escocés, es la que también se propone seguir el señor Cameron.

Como les decía, en España este sistema de generalización de las autonomías se inicia muy dubitativamente en 1931. Como bien saben ustedes, mejor que yo, el único estatuto en vigor a la entrada de la Guerra Civil era el catalán. Y después, entró en vigor el vasco. Y yo dudo mucho de que de haber seguido la república y de haber tenido una vida más larga y más pacífica, se hubieran generalizado mucho las autonomías, aunque constitucionalmente era posible.

En España, en el 78, se intenta una generalización, para lo cual caben dos soluciones: aceptar que la nación, lo que he llamado "nación dominante", es una nación como las demás y que se puede configurar como un ente dotado de autonomía como los demás, o bien fraccionar esa nación dominante en otras entidades menores, que se llaman regiones, etcétera, etcétera. Aquí se siguió esta segunda vía, se inventaron las regiones. Que no es verdad que nacieran de la iniciativa de las provincias. Esta idea de que las regiones autónomas tienen que (...) o las repúblicas federadas tienen que crearse a partir de la iniciativa de las provincias, viene de una enmienda que hicieron los llamados "federales intransigentes" en las Cortes Constituyentes de 1873, las que hubieran debido llevar a la (...) las que estaban haciendo la Constitución federal de la I República. Después, la recoge la Constitución del 31, y en teoría la del 78, pero no en la práctica porque en la práctica, al tiempo que se hacía la Constitución mediante decretos leyes, se fue haciendo el mapa político de España con la creación de las preau- 
tonomías. Y después, en la práctica, son las preautonomías las que se transforman en comunidades autónomas. Bien.

Este sistema de generalización de las autonomías iba acompañada, inicialmente, de una diferenciación entre las comunidades que habían plebiscitado en el pasado el Estatuto de Autonomía, a las que se sumó como es bien sabido Andalucía, y las demás. Pero esa era una diferenciación temporal. Y, a partir del 92, de 1992, se inicia un proceso de homogeneización -digamos- de las autonomías. Y ese proceso, que ha avanzado sobre todo a partir del 96, tiene como efecto inevitable que las autonomías -digamos- de las nacionalidades intenten recuperar su singularidad: el Estatuto, el famoso Plan Ibarretxe aquí en el País Vasco, el Estatuto catalán, el que terminó con la sentencia (...) vamos, terminó; sigue en vigor, etcétera. Y esto ha llevado, lo que a mí me parece, a una situación de crisis del estado de las autonomías. Es esta su situación de crisis la que me parece que exige una reforma constitucional porque, honestamente, creo que será muy difícil salir de esta situación por la vía de las reformas estatutarias, y el ejemplo del Estatuto catalán me parece que no debe ser desaprovechado.

Ahora bien, una reforma constitucional ha de superar un grave obstáculo político, y tropieza con grandes dificultades jurídicas. El obstáculo político es que una reforma constitucional con éxito solo puede apoyarse en una concepción de España que rechazan, hoy por hoy, todos los nacionalismos radicales, tanto el nacionalismo unitarista español como los nacionalismos independentistas, especialmente catalán y vasco. Y, naturalmente, este nacionalismo radical va a seguir existiendo siempre. Pero, lo que sí cabe, y a mi juicio es perfectamente posible, es reducir el apoyo social de esos nacionalismos radicales, de manera que la opinión mayoritaria se aparte de ellos.

Esta es una empresa, esta de reducir el apoyo social a los nacionalismos radicales, que requeriría una acción muy enérgica de todos los partidos españoles, salvo naturalmente los que profesan un nacionalismo radical, tanto de los partidos cuya base electoral es el país entero como de aquellos otros cuya base electoral está limitada a una comunidad autónoma determinada, especialmente Cataluña, el País Vasco, Navarra, y en menor medida Galicia. Esto creo que es una idea muy generalizada, nada original, y hasta el presente yo no tengo indicios, no veo indicios de que los partidos estén intentando seguir esta vía, que sería la de una reconstrucción del sentimiento nacional español en este sentido amplio, y que yo lo siento. Lo creo y lo siento. Bien.

Pero, sobre este tema -como comprenderán ustedes-, ustedes son políticos, y yo nada puedo enseñarles. Alguna mayor autoridad tengo en lo que se refiere a las dificultades jurídicas de la reforma. Estas dificultades son muchas, variadas. Hay dificultades procedimentales y dificultades que diríamos sustanciales. Y estas sustanciales, muy diversas. 
Dificultad procedimental. En el procedimiento previsto en la Constitución, el Título X, las comunidades autónomas no tienen intervención alguna en el proceso de reforma constitucional; esto es obvio. Pero, a no ser que la reforma parta de una proposición de reforma iniciada por una comunidad autónoma, salvo en esto en todo el proceso, la reforma, intervienen solo las Cortes Generales, y, eventualmente, el pueblo español en su conjunto.

Hombre, una reforma constitucional, hecha cuando todo el país lleva 30 años dividido en comunidades autónomas, y cuya finalidad específica es reformar el sistema de organización territorial del poder en el que no participen las comunidades autónomas, resulta -digamos, por lo menos- chocante. Y es un problema con el que hay que enfrentarse.

En el proyecto de reforma preparado en Cataluña por la Fundación Campalans, se sugiere una vía que quizá valdría la pena explorar, que es que la proposición -una proposición de reforma y, desde luego, la reforma constitucional a mi juicio debe partir de una proposición, nunca de un proyecto-, la proposición de reforma debería ser debatida previamente por algún género de asamblea, de órgano, de reunión, en la que estuvieran presentes todas las comunidades autónomas. Podrían ser, no sé si una conferencia del presidente o cualquier otro formato informal, porque, naturalmente informalmente -como digo- las comunidades autónomas no tienen presencia en el procedimiento de reforma, pero que satisfaría materialmente esa necesidad.

Y después vienen las dificultades sustanciales. Primera. Mantener el mapa político de España o cambiarlo. La razón de ser del actual no es fácilmente comprensible. Es decir, no solo hay una serie de comunidades uniprovinciales, o la razón de ser no parece evidente, sino que tampoco parece evidente que no fuera posible reducir el número de comunidades autónomas en aquella parte de España cuya lengua propia es solo el castellano. Creo que eso sería posible y, a mi juicio, sería bueno.

En esa parte de España, de la que yo vengo, una pregunta que para ustedes tiene sentido para nosotros carece -absolutamente- de sentido. Es decir, yo soy extremeño; por cierto, la única nación que le ganó una guerra a la nación vascongada. Hay un célebre episodio que se llama "La guerra de vascongados y vicuñas", que tuvo lugar en Potosí entre 1600 y 1623. Que, un curioso episodio del que no voy a hablar ahora, pero que vale la pena (...). Bueno, les decía, yo, como extremeño, la pregunta de "¿se siente usted más extremeño que español o más español que extremeño?", no puedo contestar porque para mí la pregunta carece absolutamente de sentido. Yo soy español y extremeño. Soy español porque soy extremeño, y soy extremeño porque soy español, ¿no? Carece de sentido. En cambio, hay otras partes de España donde esa pregunta sí tiene sentido.

Por eso, la división en comunidades autónomas de las regiones de lengua castellana, quizás, podría simplificarse algo. Pero, en fin, yo no voy a dar soluciones, sino 
señalar cuestiones que una reforma debe afrontar. Creo improbable que se logre transformar el mapa político de España, porque las entidades territoriales, una vez creadas, tienen una resistencia enorme a cambiar. Fíjense ustedes que la división provincial actual fue una solución casi de emergencia de Javier de Burgos, en 1833. Y, desde 1833, las provincias se han convertido en una especie de mónadas euclidianas de unidades que no se pueden cambiar, de manera que la creación de regiones autónomas o de repúblicas federales ha de hacerse siempre con bloques provinciales enteros, aunque esos bloques provinciales, a veces, en mi caso, en mi provincia de origen, Badajoz, los límites provinciales de Badajoz se establecieron teniendo en cuenta los límites de la lugartenencia de la Orden de Santiago. Y, manifiestamente, la provincia de Badajoz tiene un norte y un sur bastante diferenciados, que se podrían haber dividido de otra manera, pero bueno.

En segundo lugar, dificultades, de segunda, de las dificultades sustanciales que tengo aquí anotadas. El modelo de organización de la división territorial del poder. Mantener el modelo del estado de las autonomías o ir hacia una federalización. De federalización se está hablando mucho, y no sé qué se entiende por federalización. Yo entiendo en este caso, por federalización, una cosa muy simple, que es llevar el sistema de organización territorial in toto a la Constitución, de manera que los estatutos de autonomía, que si quieren pueden llamarse constituciones, pues regulen como las constituciones de los estados federados en una federación exclusivamente el modo interno de organización del poder, eventualmente algunos derechos de los ciudadanos, pero, en modo alguno, las competencias. Las competencias están en la Constitución, todas.

Es decir, abandonar de una vez, y por todas, el principio dispositivo. Creo que ahora debería ser posible hacerlo. En el 31, ya Ortega creía que hubiera sido mejor no acudir al principio dispositivo, pero bueno. Y en el 78, quizás en los momentos iniciales, no había otra manera de echar para adelante. Ahora creo que sería bueno acabar con el principio dispositivo, y llevar la división territorial del poder exclusivamente a la Constitución.

Pero eso, a su vez, implica llevar a la Constitución el famoso o la famosa -y para nosotros la crucial cuestión de la- homogeneidad o heterogeneidad de las comunidades autónomas; se siguen llevando así, pero ese problema alguna vez hay que afrontarlo.

Yo creo que lo que refleja la estructura real de España es un sistema de autonomías asimétricas; creo que las necesidades de las diversas partes de España no son iguales y que eso implica una cierta asimetría. Ahora bien, esa asimetría puede tomarse en consideración en diversos planos: en primer lugar, en el plano constituyente. Yo, no creo, ni la creo posible, ni la creo razonable, ni la creo éticamente defendible, la transformación de España en un estado confederal; simplemente así lo creo. Es decir, creo que la idea de unidad de la nación de naciones implica un principio de unidad, y que la 
Constitución debe responder a ese principio de unidad y ser una constitución y no un pacto entre naciones diversas.

Pero, también creo -con la misma sinceridad se lo digo- que la presencia de esas naciones diversas - de esas nacionalidades si ustedes quieren, o comunidades nacionales, como lo quieran llamar-, deben tener presencia también en el momento constituyente. Y que, esa presencia, no puede basarse atribuyendo a las nacionalidades, y perdónenme ustedes el término que utiliza la Constitución, una fuerza que se corresponda simplemente con el número de habitantes de la misma, porque entonces esas comunidades quedarían diluidas en el conjunto. Hay que ponderar, de alguna manera, su condición de nacionalidades, de manera que su presencia, su peso real en el proceso constituyente esté, también, no determinado solo por su población sino también por su condición nacional específica. Esto no es fácil. Políticamente, es difícil. Jurídicamente, no es fácil, pero no es imposible de resolver, tanto si el proceso constituyente se realiza solo en el seno de las Cortes Generales como si el proceso constituyente culmina también con una decisión en referéndum.

En cuarto lugar, la asimetría competencial. La asimetría competencial es el tema del que más se habla, y yo solo puedo referirme a él en términos muy primarios. La distribución de competencias entre las comunidades, sobre todo la distribución asimétrica en cualquier caso, ha de tomar en cuenta intentar salvar dos principios básicos: primero, que esas competencias asumidas -como se dice en el País Vasco-, o funciones asumidas, sean suficientes para asegurar la voluntad de autonomía de la comunidad respectiva. Y el segundo, y gran problema, es cómo se compone esa diferencia competencial con la igualdad de voto de todos los diputados en el seno de las Cortes Generales. Esto es lo que se llama en los británicos la famosa West Lothian Question. Es una cuestión que planteó ya en los años 70 un diputado por Glasgow; un diputado escocés, no independentista. Y dice: "Bueno, si Escocia recibe mayores poderes, ¿por qué un diputado de Essex podrá, yo como diputado de West Lothian podré opinar y votar en el Parlamento Británico sobre los derechos y los deberes y las leyes que se van a aplicar en Essex y, en cambio, un diputado de Essex no podrá votar sobre las leyes que se aplican en Escocia en determinada manera?". Bueno, ese es el otro problema real, y otro problema con el que una reforma constitucional ha de enfrentarse.

Y por último, el gran problema de la asimetría fiscal. Esta asimetría es la única que tiene en el presente base constitucional -qué les voy a decir a ustedes que ustedes no sepan-, pero referida solo al País Vasco y Navarra. Hay dos cuestiones aquí: la primera, la de si este sistema fiscal podría generalizarse al resto del país. Ahí toco de oído, porque yo no soy experto en la materia, ni muchísimo menos, pero según las opiniones que he leído de expertos reconocidos, por ejemplo un catedrático de aquí, de la Universidad del País Vasco, Ignacio Zubiri, y otros muchos, la generalización es prácticamente imposible. Ángel de la Fuente, un experto del CSIC, la cree posible pero modificando algo los parámetros actuales. 
En segundo lugar, ¿puede mantenerse en sus términos actuales a un referido solo a dos comunidades determinadas? Yo sé que es una opinión que seguramente ustedes no van a seguir, pero les tengo que decir lo que pienso y no lo que el auditorio quiere oír. Y, a mi juicio, en sus términos actuales, es muy difícil mantener, no la Ley de Concierto, pero sí la Ley del Cupo y el cálculo del Cupo. Es decir, es, como saben ustedes, el llamado ajuste del IVA y el cálculo de las competencias no asumidas, del coste de las competencias no asumidas, etcétera, está dando lugar a resultados sorprendentes de que sea mayor el flujo fiscal del Estado en la Comunidad del País Vasco o de Navarra, que viceversa.

Pero es que hay más, entre las competencias no asumidas no se toma en cuenta que, al menos, no en la medida que a mí me parece necesaria, una competencia que no es asumida y que, además, no es asumible, que es la competencia para asegurar la redistribución de la renta nacional.

En el paso del estado liberal decimonónico al paso al estado social, se produce cuando, a partir de 1894, aproximadamente, en Alemania, y en esa misma fecha, aunque de manera fracasada, en el Reino Unido -porque en el Reino Unido el impuesto sobre la renta no logró establecerse hasta que se reformó la Constitución para atribuir al congreso esas competencias-, cambia absolutamente la concepción del impuesto. Y la concepción del impuesto deja de ser, simplemente, un modo de retribuir los servicios prestados por el estado, para ser concebido también, incluso muy principalmente, como un instrumento de redistribución.

Esto es lo que hizo posible el estado social y un equilibrio entre democracia y capitalismo, que se ha podido mantener con éxito hasta la llegada de la señora Thatcher y el señor Reagan, que desde entonces ha entrado en declive, y que, a juicio de algunos, se ha roto por entero en nuestros días. Y, como algunos preconizan, hay que abandonar la idea de estado social para atenerse a la de estado caritativo. Sustituir la idea de política social por la de beneficencia, etcétera.

Yo soy un dinosaurio de 84 años, como le he dicho, y no quiero renunciar a la idea del estado social y de política social. Y creo que se debe seguir utilizando el impuesto como un instrumento de redistribución de la riqueza, un instrumento para reducir las desigualdades económicas o compensar sus efectos.

Ya sé que esto es muy difícil. En el estado deudor, cuando el estado depende más de los créditos que obtiene en los mercados que de los tributos de recauda, y que, en consecuencia, está obligado a servir a las vez a dos señores: el pueblo del estado, que es el de la soberanía, y el pueblo del mercado, que es un pueblo internacional, de contornos más definidos, incluso, poder que se expresa, no a través del voto, sino a través de los tipos de interés, es un poder muy fuerte.

Pese a eso, yo no renuncio a la idea de estado social. Creo que el estado social requiere una tarea de redistribución de rentas. Una tarea de redistribución de rentas que no puede solo entre individuos, cuando la comunidad política está dividida en comu- 
nidades distintas, las comunidades de autonomía, sino, también, de alguna manera, entre comunidades autónomas.

Y desde ese punto de vista, yo creo que el cálculo actual del Cupo no toma en cuenta en manera suficiente las necesidades de redistribución interterritorial, digamos, de las rentas. Hay una aportación para el Fondo de Compensación Interterritorial, un fondo muy pequeño. Por ejemplo, tendría que incluirse, me parece, en el Cupo una aportación importante correspondiente a la riqueza relativa del País Vasco, al fondo de suficiencia de servicios fundamentales y cosas por el estilo. Pero, en fin.

Con esto yo les he hecho una exposición a grandes líneas de mi visión del problema. Y supongo que para ustedes tiene más interés las preguntas, las respuestas que yo pueda dar a sus preguntas. Aunque yo me temo mucho, que como le he dicho, ese interés tiene poco fundamento, porque poco tendré yo que contestarles.

Muchas gracias.

LANTALDEAREN ANTOLATZAILEAK:

Muy bien, muchas gracias.

Vamos a abrir el turno de los grupos. En nombre de UPyD, tiene la palabra Gorka Maneiro.

MANEIRO LABAYEN jaunak:

Sí. Muchas gracias, señor Rubio. Muy interesante su intervención. Y por supuesto que nos viene muy bien a todos los grupos que formamos parte de esta ponencia para tener una opinión más en relación a esta cuestión que tanto nos preocupa.

Vaya por delante que a nosotros, a mí en concreto, pues también me parece que el artículo publicado en El País hace un par de días, Un proyecto para España de Tomás Pérez Vijo, pues, es, ciertamente, un artículo muy interesante donde se recogen reflexiones a tener en cuenta al menos, ¿no?

Entrando en la cuestión, lo cierto es que aunque esta es una ponencia para hablar del autogobierno vasco y explorar, supuestamente, las posibilidades de llevar a cabo una reforma del Estatuto de Gernika, lo cierto es que ya son, prácticamente, mayoría los comparecientes que vienen a señalar la necesidad de reformar la Constitución española. Creo que han sido, no sé si todos, pero, casi todos, los comparecientes que han señalado la necesidad de, antes que nada, plantear la necesidad de reformar la Constitución española.

Y lo cierto es que de los ocho comparecientes anteriores que ya han comparecido, yo diría que al menos cuatro de ellos, o en concreto cuatro de ellos, de un modo u otro, han defendido la necesidad de reformar la Constitución española en clave federal. Y me refiero expresamente al señor Montero, al señor López Basaguren, al señor Javier 
Tajadura, y al señor Joseba Arregi. Ahí está todo lo que ellos han dicho en relación a esta cuestión.

Por ejemplo, el señor Manuel Montero decía expresamente que hay que ir hacia un estado federal que no sea asimétrico. El señor López Basaguren defendía básicamente lo mismo e incluía críticas al sistema de Concierto Económico. No tanto, que también, en su comparecencia en esta ponencia, como en los diferentes escritos publicados en los medios de comunicación en los diferentes periódicos en los últimos años.

Por su parte, el señor Javier Tajadura decía expresamente que el federalismo no tiene nada que ver con posiciones singulares, derechos históricos o realidades nacionales. Y, a su vez, defendía la necesidad de reformar la Constitución española para ir hacia un estado federal simétrico.

Y, por último, el señor Joseba Arregi decía expresamente que las federaciones tienden a la simetría, ¿no? Y defendía, por lo tanto, la necesidad de configurar un estado federal simétrico más allá de las dificultades políticas que puedan existir en los momentos actuales.

Yo le quiero preguntar expresamente, aunque usted ya ha respondido algo, ya ha dicho algo, si usted considera viable una reforma de la Constitución española en clave federal. Usted ha hablado y ha señalado que quizás fuera posible o deseable una cierta asimetría, y yo le quería preguntar cómo se conjuga esto con los principios de solidaridad e igualdad que supuestamente son principios que van unidos al principio del federalismo.

En todo caso, ¿cuál sería la reforma constitucional que usted plantearía? ¿Con qué objetivos y bajo qué principios?

Y también quería preguntarle si considera usted que los nacionalismos disgregadores, moderados o radicales -yo creo que todos son en el corto plazo o en el largo plazo nacionalismos disgregadores-, si usted considera que aceptarían una reforma de la Constitución como la que usted estaría dispuesto a plantear; más allá de las dificultades procedimentales que puedan existir, ¿no?

Es decir, que hay partidos políticos o hay cierta opinión pública que viene a señalar la necesidad de reformar la Constitución española para acomodar a los nacionalismos. Yo creo que esto es materialmente imposible. Hace unos minutos, incluso, el propio portavoz del Gobierno Vasco reclamaba en una entrevista radiofónica que se abra un debate para la reforma de la Constitución española. Pero me da la sensación de que lo que los nacionalismos quieren en última instancia no es tanto reformar la Constitución española, sino romper el país para configurar un estado propio.

En todo caso, en fin, estas son las preguntas que yo tengo.

Y, para terminar, pues también quería decirle que no es usted el primero que viene a esta ponencia a criticar el sistema de Concierto Económico, más concretamente el 
cálculo del Cupo. Y a nosotros nos parece muy correcto todo lo que usted dice, porque creo que es un hecho evidente, ¿no? Que existe esa imposibilidad de trasladar un sistema como el Concierto Económico o la imposibilidad manifiesta y clara de trasladar el sistema de Concierto Económico al resto de comunidades autónomas, tal y como han expresado y han explicado por activa y por pasiva todos los técnicos y todos los especialistas en la cuestión.

Usted hablaba de resultados sorprendentes. Efectivamente, cuando hablamos de resultados sorprendentes, de lo que estamos hablando expresamente es que Euskadi y Navarra pues no aportan a la solidaridad interterritorial, y, evidentemente, nosotros estamos de acuerdo con usted en que esto hay que cambiarlo para garantizar la máxima igualdad de la ciudadanía.

Ya digo que esto mismo han venido a plantearlo los comparecientes que han defendido la necesidad de reformar la Constitución española para ir hacia un estado federal simétrico; es decir, que usted no es el primero, sino que incluso se puede decir que ya son mayoría, son 5 de 9 comparecientes los que señalan en esta ponencia que, efectivamente, el cálculo del Cupo implica un privilegio.

Nosotros lo compartimos en este Parlamento. Pues, bueno, solo hay un parlamentario de 75 que defiende esto, pero creo que se abre paso esta opinión. Y que, en todo caso, pues lo importante de esto es, en definitiva, poner sobre la mesa la necesidad de reformar la Constitución española para acabar con todos los privilegios, reformar el Estado de las autonomías, garantizar la máxima solidaridad y garantizar la máxima solidaridad.

En fin, y por último y para terminar, el señor Javier Tajadura hace apenas dos semanas, además de defender ese estado federal simétrico, criticaba la politización actual del Tribunal Constitucional. Dada su experiencia, también quería preguntarle sobre la cuestión. Qué le parece, si usted comparte, si piensa que habría que impulsar también reformas en ese sentido para despolitizar y, por lo tanto, profesionalizar el Tribunal Constitucional español.

Y creo que de momento nada más. Han sido muy interesantes todas sus reflexiones.

Gracias.

RUBIO LLORENTE jaunak:

Yo preferiría, porque así se hace más (...) 
Vamos a ver. Si yo entiendo bien su cuestión, aparte de las coincidencias sobre la necesidad de reformar el sistema del cálculo del Cupo, se puede reducir simplificándola a tres cuestiones: primero, la última, la politización del Tribunal Constitucional; segundo, lo de si cabe acabar con los nacionalismos; y, tercero, lo de la asimetría e igualdad y solidaridad. Creo que esas son las tres cuestiones.

Empezando por la última, la politización del Tribunal Constitucional. Mire usted, el Tribunal Constitucional, desgraciadamente, visto actualmente, en general, por los españoles como una especie de tercera cámara donde se dirimen las cuestiones que se han dirimido antes en las Cortes y en donde las minorías buscan un remedio frente a la derrota que obtuvieron en sede parlamentaria. Entonces, esto es un mal que debe ser enfrentado, pero cuya raíz no está tanto -en contra de lo que cree el señor Tajaduraen el modo de elección de los miembros del tribunal, que es bastante común, como en las competencias del tribunal, y, sobre todo, en la legitimación para acudir al Tribunal Constitucional.

De lo que ha pasado tengo yo bastante culpa, no como magistrado del Tribunal Constitucional, sino como asesor jurídico de la ponencia que hizo la Constitución. En la ponencia que hizo la Constitución, sin duda, era yo el que más derecho constitucional sabía, sabía más que Fraga, desde luego, y más que el resto de los miembros, que no es que fueran ignorantes, pero, en todo caso, el derecho constitucional que yo sabía era solo un derecho aprendido en los libros; no aprendido en la práctica y que no había tenido ocasión de vivir. Y yo, por desgracia, leo alemán y mi formación de constitucionalista se había hecho sobre todo a través del derecho constitucional alemán, que era el de más prestigio en la Europa de la época y sigue siéndolo. Y cuando hubo que hacer el proyecto de ley del Tribunal Constitucional, que se nos encomendó a una (...) vamos, en la Constitución, yo metí el principio de legitimación de las minorías parlamentarias para el recurso de constitucionalidad; porque eso existía en Alemania, existía en Alemania, en Austria y creo que en ningún otro sitio.

Y, ahora, 30 años después, me parece que cometí un gravísimo error, porque si las minorías parlamentarias están legitimadas para acudir al Tribunal Constitucional, inevitablemente lo harán cada vez que sean derrotadas en el Parlamento, las Cortes Generales, donde sea. Entonces, a mi juicio, una de las cosas que habría que hacer en la reforma constitucional era eliminar la legitimación de las minorías parlamentarias para acudir ante el Tribunal Constitucional. Que puedan acudir los gobiernos, que puedan acudir tanto el Gobierno nacional como los gobiernos de las comunidades, y el Defensor del Pueblo, pero no las minorías parlamentarias.

Un recurso directo de inconstitucionalidad es siempre un instrumento muy peligroso, y se convierte en un instrumento explosivo cuando se pone en manos de las minorías parlamentarias. Esa legitimación no existe en Inglaterra, no existe en Italia, no existe, por supuesto, en los Estados Unidos, donde no hay recurso directo ningu- 
no, etcétera, etcétera. Entonces, yo creo que habría que hacer eso. Se puede modificar el sistema de elección de los magistrados, pero, sobre todo, hay que evitar que los magistrados, que el Tribunal Constitucional, pueda ser utilizado por las minorías parlamentarias para llevar allí las disputas políticas, la condonación de las disputas parlamentarias.

Y se ha dicho, yo tuve ocasión de expresar esta opinión. Es un matiz, pero es un matiz que es interesante porque en eso disentía de Javier Tajadura. Cuando una proposición de ley que suscribieron o hicieron en paralelo el Partido Popular y el PSOE para reintroducir el recurso previo de inconstitucionalidad, yo tuve ocasión de decir a quien quiso oírme que eso era un error gravísimo, porque esa fórmula, ese control previo de inconstitucionalidad podría, debería hacerse no a través de la vía de recurso, sino de dictamen preceptivo.

No es lo mismo llevar el control previo de constitucionalidad al Tribunal Constitucional, como a través de un recurso que hace un partido frente a otro partido, que llevarlo como un dictamen preceptivo que, en todo caso, obligue al Tribunal Constitucional, no a dirimir la contienda política entre un partido y otro, sino a dar su opinión en abstracto y objetivo. Y ahí, por ejemplo, Javier Tajadura estaba en desacuerdo por razones que, a mi parecer, de lo que llamaría Pascal (...).

Bien, en segundo lugar, la posibilidad que a través de la reforma constitucional desaparezcan los nacionalismos. No, en absoluto, en absoluto. Ninguna reforma constitucional va a acabar con los nacionalismos radicales. Los nacionalismos templados no son rechazables, sino, a mi juicio, son indispensables. El sentimiento nacional es la base de la convivencia política, y sin el sentimiento nacional es difícil concebirle la convivencia política.

Otra cosa son los nacionalismos radicales, tanto en una sociedad con la estructura como la nuestra, una estructura compuesta, tanto los nacionalismos radicales que niegan la existencia de esas diferenciaciones, como los nacionalismos radicales que insiste en que esas diferencias son tales que solo se puede vivir separados. Eso no se va a acabar nunca. Pero yo creo que a la (...) no se puede acabar nunca, o, por lo menos, no en el corto o en el medio plazo. Pero creo que quizás en el medio plazo, y quizás con más (...) en el largo plazo, se les puede restar apoyo social, de manera que se conviertan en posturas políticas más bien testimoniales. Eso lo creo firmemente. Lo he creído, en el caso de Cataluña creo que ahí fue una de las razones por las que me parece que la política del Gobierno español ha sido equivocada en ese tema, porque creo que hay muchas razones para restarle apoyos, no al nacionalismo, sino al nacionalismo independentista o radical; y también, por supuesto, al nacionalismo unitarista español, que piensa en términos que no se corresponden en absoluto con la realidad.

Y, por último, la cuestión más difícil, a la que usted ha aludido y que es difícil, no porque haya aludido usted a ella, sino porque sustancialmente es muy difícil, es la opción entre simetría o asimetría. 
Es verdad, es verdad que en una concepción clásica del federalismo, se considera que el federalismo implica una igualdad jurídica -no fáctica, no económica, no social-, una igualdad jurídica de todas las entidades federadas. Incluso se ha llegado a decir, por ejemplo en la obra de Carl Smith si no recuerdo mal, en fin, del nacionalismo alemán que ha sido siempre muy rotundo, que por eso el federalismo solo era posible en estados con una fuerte conciencia nacional. Yo creo que no es así, creo que no es así, yo creo que cabe el federalismo en estados diferenciados, políticamente diferenciados. Y creo que el federalismo en estados políticamente diferenciados exige algún grado de asimetría.

No imagino en el Reino Unido, los distintos condados de Inglaterra tengan la misma necesidad de voluntad de autonomía que Escocia o que Gales o que Irlanda del Norte. Y tengo la evidencia de que esa es también la situación en España.

Ahora bien, dicho eso, esa diferenciación, debe ser compatible con los principios de igualdad y solidaridad. Evidente, evidente. Pero eso es lo que he intentado explicar en mi introducción inicial, la solidaridad es susceptible de grados distintos de intensidad. Todos nos sentimos mucho más solidarios de la familia que de los vecinos, todos, o por lo menos la mayor parte de los humanos, de los españoles, nos sentimos más solidarios de la familia que de los vecinos. Probablemente, más solidarios de nuestro pueblo que de los del pueblo de al lado. Me atrevo a pensar que los guipuzcoanos se sienten más solidarios de los guipuzcoanos que de los vizcaínos, etcétera, etcétera. Y esos grados, esos distintos grados de solidaridad, justifican también que las aportaciones de solidaridad al común sean diferenciadas de acuerdo con la existencia de eso, lo que he llamado espacios de solidaridad distinta.

Y después está el problema de la igualdad. Vamos a ver, en la Ética a Nicómaco -perdonen ustedes que me ponga un poco profesoral-, en la Ética a Nicómaco se dice, si no recuerdo mal, que la igualdad exige tratar de modo igual a lo que es igual y de modo diferente a lo que es diferente. Entonces, si partimos del supuesto de que algunas diferencias estructurales hay en el seno de España, la igualdad no se rompe porque unas partes de España reciban algún tratamiento diferente al de otras.

Como les he dicho también, ese grado de asimetría es muy difícil de poner en práctica, porque debe respetar dos principios: de la suficiencia, de ese mayor poder, digamos, para satisfacer las necesidades de la comunidad que las reclama, y la del mantenimiento de una igualdad sustancial con el resto. Es decir, que debe de ser un grado de solidaridad o de desigualdad que sea compatible con el mantenimiento de alguna igualdad sustancial.

Eso, perdónenme ustedes, pero eso es posible y eso lo vivimos todos los días. En materia de derechos, por ejemplo, no negamos los europeos que los africanos tengan derecho a la vida y tengan derecho a no ser torturados, a no ser sometidos a tratos inhumanos o vejatorios, etcétera, etcétera. Pero, en cambio, no tenemos ningún reparo a aceptar que no tienen el mismo derecho que nosotros a comer bien o a tener buenos servicios sanitarios. Y no tenemos mala conciencia, o por lo menos parece que 
no tenemos mala conciencia, al poner vallas en Melilla o al impedir el desembarco de centenares o miles de emigrantes que vienen impulsados por el hambre y el miedo en Lampedusa, en donde sea.

Entonces, el ejemplo no es bueno, quizás, pero sí sirve para ilustrar lo que quiero decir. Yo, como extremeño, no solo es que yo no tenga necesidad como extremeño de que se le den a mi comunidad unas competencias especiales en materia lingüística, que, por supuesto, no las tengo. Lo que yo quiero aprender, lo que quiero que se le enseñe bien a los extremeño es el castellano, que no lo hablen mal como lo hablamos, $\mathrm{u}$ otras competencias lo mismo que en el (...), sino que tampoco tengo, por ejemplo, un tema tan evidente, la policía. ¿Qué necesidad tenemos los extremeños de policía si la mayor parte de los guardias civiles y de los policías son extremeños o andaluces o murcianos? ¿Qué necesidad tengo de eso? Eso es una proyección de la realidad, y como en eso en otras cosas. Y no me puedo sentir en modo alguno tratado de manera desigual porque no se me da lo que yo no quiero.

Lo que es falso es creer que para ser igual yo tengo que querer lo que quieren los demás. El famoso principio de emulación de Ortega.

Bueno, no puedo razonar más, hasta ahí he llegado.

LANTALDEAREN KOORDINATZAILEAK:

Muchas gracias.

En nombre del grupo Popular tiene la palabra el señor Barrio.

BARRIO BAROJA jaunak:

Sí, muchas gracias.

Pues, simplemente, al no haber estado en la totalidad de la intervención del señor Rubio Llorente, lamentablemente, pues agradecer su presencia, agradecer sus explicaciones. Agradecer también el esfuerzo y la respuesta también a mi compañero que, desde luego, habrán completado sin duda la exposición inicial que nosotros trataremos y releeremos con interés.

Muchas gracias.

RUBIO LLORENTE jaunak:

Muchísimas gracias, muy cortés. Cortesía vasca.

Ahora, tiene la palabra el señor Prieto del grupo Socialista. 
Gracias, señor Rubio Llorente por sus explicaciones. La verdad es que es un placer escucharle y también es un placer ver cómo combina la ironía con la reflexión a fondo sobre los temas que usted bien conoce.

Y abusando un poco de usted, yo quisiera que profundizara en algunas cosas más a partir de algunas consideraciones que le voy a hacer.

La primera es en relación con el Concierto. Es cierto que el Concierto nos da una singularidad, nos da una diferenciación a vascos y navarros en relación con el conjunto del Estado, pero también es cierto que el Concierto está íntimamente relacionado con nuestro nivel competencial. Es decir, el País Vasco asume responsabilidades políticas y responsabilidades de atención económica y social a su ciudadanía, que por razones de no tener Concierto Económico no lo hacen otras comunidades autónomas.

Muchas veces, cuando se habla del Concierto Económico, así en plan generalista, puede dar la impresión de que nosotros recibimos gracias a ese Concierto una capacidad fiscal y una capacidad de recaudación y una capacidad de gasto, y junto con el Cupo, mayor que los demás para hacer las mismas cosas que los demás. Y, obviamente, no es así. Entonces, yo creo que esto también tendría que inspirar un cierto mensaje de moderación, de tranquilidad, de sosiego.

Cualquiera que plantee en una comunidad autónoma, que no sea Navarra o el País Vasco, que hay una diferencia en esta capacidad económica y fiscal, tiene razón, y que hay una diferenciación, tiene razón. Ahora, de ahí a que eso termine asimilándose popularmente a que pueda ser un agravio comparativo, que pueda ser una ventaja sin justificación, sin razón, sin contrapartida para los ciudadanos, yo creo que es donde hay que poner un poquito el acento.

Por eso yo quisiera que, un poco, usted pudiera profundizar en si desde esa perspectiva esa singularidad es una singularidad que a su juicio es asumible o debe ser asumible por el conjunto del país, por el conjunto de España, por el conjunto de las comunidades autónomas. $\mathrm{O}$, por el contrario, como sostienen algunos, también en esta Cámara, como ya le han reflejado, hay que acabar con el Concierto Económico, hay que acabar con el Cupo.

Pasaría algo parecido en relación con el Cupo, yo le quiero decir que el Cupo es una cantidad que se paga al Estado pactada, salvo en los últimos años. Ahí hay un, desde el año 2007 hay un problema con el Cupo en general, y luego con la liquidación al Estado más recientemente, porque, por ejemplo, en el año 2014 el Estado en los presupuestos generales dobló la cantidad de liquidación de Cupo sin un pacto previo; sin haberlo tratado directamente como corresponde en la Comisión Mixta, y, bueno, pues haber hecho de esa consignación un acuerdo.

Para el año 2015, que se presentó ayer el presupuesto, el proyecto de Presupuestos del Estado, vuelven a insistir en la misma cantidad. Es decir, el Estado ha llevado a mil 
quinientos y pico millones lo que se tiene que pagar de Cupo, frente a los ochocientos y pico que se liquidaron en el año 2013.

Bueno, yo creo que la primera cosa que hay que reflejar es que hasta ahora el Cupo ha sido pactado, y que ahora, cuando no es pactado, se ha hecho unilateralmente desde un Gobierno un reflejo doble de lo que se tiene que abonar.

Pero, en cualquier caso, y yendo a los números. Para a veces situar la justicia o la injusticia, la solidaridad o la insolidaridad del Cupo, vamos a suponer que ya que el Estado unilateralmente ha pasado de los ochocientos y pico millones a los 1500, el Estado ha hecho bien ahora el cálculo, y ese es el cálculo real que corresponde de las competencias que regula el Estado y que no son transferidas, y por las que nosotros tenemos que pagar.

No creo que esa diferencia de 800 millones, que pueden ser muy importantes para el País Vasco, sean realmente importantes para el conjunto del Estado. Sin despreciarla, aquí no se desprecia ninguna cifra, y menos en los momentos que estamos viviendo. Pero no parece que la diferencia resolvería los problemas económicos y sociales y de desigualdad que hay en el Estado. No parece que la diferencia arreglaría la sanidad, arreglaría la educación, arreglaría las inversiones en la alta velocidad, en las infraestructuras, etcétera. Por lo tanto, a mí también me gustaría que ahí pudiese emitir una opinión un poco más sobre lo concreto, porque, claro, a veces hablamos del Cupo. Usted ha señalado: el Cupo está mal hecho, está mal calculado, es insuficiente, el Fondo de Compensación Interterritorial es también insuficiente. Y bueno, a mí me gustaría saber por qué. ¿Por qué es insuficiente? Porque, probablemente, para que sea suficiente, tendríamos que llegar a una cifra. Si es insuficiente una cantidad tendríamos que llegar a una cifra, a cuál.

Y la última cosa sería qué opina de algo que es también un recurso político, que está provocando un problema enorme de relación entre las comunidades autónomas y las competencias que tiene el Estado en relación con el abuso de la legislación básica. Aquí, cada vez que desde el Gobierno actual, de España, se quiere intervenir en el conjunto de las comunidades autónomas -se tengan competencias o no se tengan competencias- se acude a la legislación básica y se limita enormemente esto, y esto es también una fuente de conflicto que es perfectamente resoluble. No hace falta reformar la Constitución para respetar las competencias y para que la legislación básica no invada competencias que ya están transferidas a las comunidades autónomas.

Nada más.

RUBIO LLORENTE jaunak:

Empezando por esto, ¿por qué dice usted que no hace falta reformar la Constitución para acabar con la indefinición que resulta del concepto de legislación básica? La 
opinión generalizada es que el Tribunal Constitucional ha hecho la interpretación más amplia posible en favor de las comunidades autónomas del concepto de legislación básica.

Entonces, yo una de las razones por las que -a mi juicio- hay que llevar todo el sistema de limitación de competencias a la Constitución, es porque, por esa vía permite una solución más clara, menos confusa y menos indeterminada y sujeta a abusos que la solución actual, que la delimitación competencial resulta de una combinación de preceptos estatutarios con preceptos constitucionales.

A veces los preceptos (...) eso ha dado, por ejemplo, que a veces los preceptos constitucionales no solo se hayan interpretado en el sentido de preceptos estatutarios, sino que han terminado identificándose en la letra con ellos.

Por ejemplo, el artículo 149.1.13, las competencias del Estado en materia de planificación real de la economía, se ha terminado interpretando en la fórmula que decía el estatuto catalán de competencias del Estado sobre la dirección general de la economía para evitar (...).

Bueno, en todo caso, eso, como le digo a usted, es una de las razones por las que yo creo que es mejor acudir a una reforma federal que acudir a (...) el intento de delimitar las competencias exclusivas por vía estatutaria fracasó con el Estatuto de Cataluña. Y estaba condenada al fracaso, a mi juicio, desde el origen. Entonces, una delimitación más clara de competencias en la Constitución permitiría evitar este problema.

Ningún sistema federal del mundo permite eliminar los conflictos competenciales. En los Estados Unidos, las cláusulas generales, por ejemplo, la cláusula del comercio entre estados, o cláusulas semejantes, o no digo nada la de los poderes implícitos, que son muchísimo más invasivas, muchísimo más invasivas que la de legislación básica. Pues eso da lugar a, es una fuente continua de conflictos políticos y jurídicos. Que no se (...) con la frecuencia aquí en España, por fortuna para ellos, en el Tribunal Constitucional, en su caso en la Corte Suprema, porque allí no exige el recurso directo. Pero, en fin, estas son cuestiones, en cierto sentido, al margen de mi intervención.

La cuestión que usted me (...) en la que ha centrado la suya es en el tema del Concierto y del Cupo. Yo no voy a entrar en la justificación histórica del Concierto, y por qué se llama así, porque ha existido así, etcétera. Existe el (...). La disposición adicional de la Constitución se ha interpretado en ese sentido y esa interpretación ya es difícilmente reversible. Yo he hablado solo de que -según una opinión generalizada- que yo tomo de los expertos, el Cupo, ahora está mal calculado. Está mal calculado porque se calcula mal el costo de las competencias no asumidas, se calcula mal el ajuste del IVA y no se toma en cuenta las necesidades de redistribución de la renta, para hacer un política social, que es la base de la política social, por eso me causa cierta sorpresa que un representante del Partido Socialista centre en esto su intervención. Pero, en fin, eso no es (...) es perfectamente comprensible. 
Mire usted, es cierto lo que usted dice, absolutamente cierto. Por mucho que se eleve el Cupo del País Vasco, no va a solucionar los problemas económicos de España, ni los problemas de las infraestructuras, ni siquiera los problemas de política social. Desgraciadamente, las cantidades que se necesitan son mucho mayores para eso. Pero esa no es la cuestión en absoluto. No es la de la suficiencia o insuficiencia de la aportación navarra, o del Cupo vasco, para resolver los problemas económicos de España. El problema no es ese en absoluto. El problema es el de la justificación ética de las dimensiones de ese (...) de la cantidad económica, de la dimensión económica del cupo, de la aportación. Y ese es el problema que yo he planteado y lo que a mi juicio resulta problemático.

Según los cálculos de los expertos -que yo no soy, pero sí que los leo, claro- la financiación per capita en el País Vasco es un 65 superior a la del resto del Estado. Y eso no se corresponde con la diferencia real de riqueza entre el País Vasco y el resto del Estado.

En la línea de regresión en donde se señala la correspondencia (...) vamos, que siguen trazando, el trazado de la correspondencia entre el nivel de renta y flujos fiscales, las comunidades más ricas, es decir, Baleares, Cataluña, Madrid, Rioja, etcétera, aparecen muy por debajo de la línea de regresión, como corresponde. Porque el flujo entre la comunidad y el Estado tiene que ser, naturalmente, negativo. El País Vasco, excepcionalmente, a pesar de ser más rico que la media, aparece por encima de la línea de regresión. Eso, para mí, es un problema de cierta importancia, ni en modo alguno por lo que el incremento de la aportación del Cupo pueda suponer para resolver los problemas económicos de España, sino porque es una de las razones que hacen que en España se vea con recelo, o con hostilidad, o con antipatía, la autonomía vasca. Es por eso.

Y eso, ya le digo a usted yo, ahí, como le he dicho al comienzo, un poco toco de oído, lo que yo pienso no es resultado de investigaciones propias -que no estoy en condiciones de hacer-, pero sí es la consecuencia que yo he sacado de la lectura de expertos que me merecen respeto y les he dado a ustedes antes los nombres. Es cuanto le puedo decir.

LANTALDEAREN ANTOLATZAILEAK:

Muchas gracias.

Ahora tiene la palabra el señor Arraiz, en nombre del grupo EH Bildu.

ARRAIZ ARBADILLO jaunak:

Buenos días, lo primero agradecerle su intervención.

Y en segundo lugar, queríamos hacer una pregunta, una pregunta que viene de parte de unos nacionalistas radicales y disgregadores. Una pregunta sencilla, seguramente 
que necesita una respuesta bastante más compleja. Todo el mundo esgrime, -no solo en este ámbito, sino también en otros ámbitos- la posibilidad, y no solo la posibilidad, sino necesidad de una reforma constitucional, como si fuera a resolver todos los problemas que tiene el Estado español. Lo cual lo veo realmente complicado, pero así se esgrime por todas las partes que la piden, que la solicitan.

¿Qué posibilidades -y le pregunto como magistrado del Tribunal Constitucional y como experto en derecho constitucional-, qué posibilidades existen de que en esa reforma constitucional pueda encajar el derecho a decidir que reclama la nación vasca, la nación catalana y la nación gallega?

RUBIO LLORENTE jaunak:

Pues, mire usted, mi pregunta [sic] puede ser muy breve, y dicho con todo el respeto. Si el derecho a decidir se entiende como derecho a la independencia por voluntad propia, ninguno. Es mejor ser claro y ser rotundo. Ninguno. Es decir, no creo que sea posible en una constitución, ni siquiera en una constitución confederal, que se reconozca a las partes componentes la posibilidad de acceder a la independencia por su sola voluntad.

Ese problema, desde luego, no lo resuelve la Constitución. Y tiene usted razón, es decir, la reforma constitucional, si lo que se quiere es resolver ese problema, la reforma constitucional para eso no sirve. Mas soy tan claro como usted y tan respetuoso como usted. Otra cosa no le puedo decir. Yo le he dicho que, respetando como respeto profundamente sus sentimientos, cómo no, sería disparatar (...), sí creo que es posible que el número de vascos que se sienten identificados como usted, dicen la (...) que no tenga un peso político importante, y que, de esa manera, pues el problema de la independencia no se plantee. Pero eso es (...) usted diría que es wishful thinking. Pues a lo mejor.

ARRAIZ ARBADILLO jaunak:

El tiempo dirá.

RUBIO LLORENTE jaunak:

El tiempo dirá.

LANTALDEAREN ANTOLATZAILEAK:

Muchas gracias.

Y por último, en nombre del grupo Nacionalistas Vascos, tiene la palabra el señor Egibar. 
RUBIO LLORENTE jaunak:

El señor Egibar me ha recibido en este Parlamento.

EGIBAR ARTOLA jaunak:

Sí señor. Hemos coincidido y (...) nuevamente agradecer-como el resto de compañeros- su presencia y su aportación.

Hemos leído últimamente, además con mayor detalle, sus trabajos y sus artículos con respecto a preguntas como la formulada por el señor Arraiz y demás en los últimos tiempos, que tan de moda se han puesto no sé si los nacionalismos radicales o moderados, o ambos juntos, en Cataluña. En todo caso, lo de radical, si vamos al significado de la palabra es ir a la raíz. Raíz. Y desde una forma moderada, pero intentando aportar desde la raíz, me ha resultado llamativa la relación que hace en relación a restar apoyos a los nacionalismos, los moderados y radicales, buenos o malos en función del nivel (...).

RUBIO LLORENTE jaunak: No, no, no, no.

EGIBAR ARTOLA jaunak:

Vale, entonces retiro lo de buenos.

Buenos o malos en el sentido de que se puedan colmar los niveles de satisfacción que exija cada uno de esos nacionalismos, ¿no? Pero de su planteamiento se deduce que algún problema político hay, y que la Constitución tendría que dar satisfacción, o buscar el punto de suficiencia para que esos nacionalismos que, al parecer, según otras intervenciones, son insaciables, pues no tienen límite en sus pretensiones.

Entonces, en la medida en que usted participó directamente, como ha dicho, ha referido en su intervención, en el periodo constituyente, de la mano de los que después se denominaron padres de la Constitución, asesorándoles. En lo que se refiere a los anclajes del denominado, se ha hablado, Concierto Económico, en la disposición adicional de la propia Constitución, están también la derogatoria de las leyes abolitorias (...). En todas esas cuestiones, que después se llaman también bloque de constitucionalidad, ¿hacen de los territorios vascos -que después, en el Estatuto vasco, pasa a la consideración de que el pueblo vasco no renuncia a los derechos que le pudieran corresponder en virtud de su historia y demás- la configuración de un sujeto político que pueda entablar desde la relación política, el diálogo con el Estado central o los poderes del Estado, una configuración diferente a la actualmente existente? 
O sea, en la línea, o en el sentido de buscar esa convivencia política, pero desde el respeto a la existencia también de un pueblo, que es el pueblo vasco, que en este momento participa de una estructura política constitucional que es la vigente, pero que tiene su historia. Porque cuando la propia Constitución dice que ampara y respeta los derechos históricos de los territorios forales está amparando y respetando unos derechos anteriores a la propia Constitución. Y si tiene una configuración, después, de pueblo (...). Bueno, desde el diálogo y la negociación o corresponsabilidad, ¿qué nuevos escenarios se pueden alumbrar?

Porque también decía usted -perdón, eh- en una de las entrevistas, con respecto a una pregunta formulada como el señor Arraiz, que en el caso de Cataluña haría falta una doble consulta: una para conocer la opinión de los propios catalanes; y si estos quisieran un estado, o un estadio de independencia, que sería obligada una segunda consulta, en toda España, para dilucidar la cuestión. No sé si se refleja bien en una entrevista esto que se le atribuye, pero, en ese contexto, en la búsqueda de formas de diálogo o de entendimiento posible, pues, qué le sugiere todo esto que está sucediendo en este momento, ¿no?

Bueno, intento contestar a su pregunta, que no es especialmente concreta.

En referencia, primero, a lo de Cataluña. Yo he sostenido, de acuerdo con Ruiz Soroa en el País Vasco y de acuerdo con Francesc de Carreras en Cataluña, que sería muy bueno que se reformara la ley orgánica sobre diversas modalidades de referéndum, para que las comunidades autónomas pudieran llevar a cabo referéndum, regulándola de modo que cuando la pregunta sometida a referéndum tuviera incidencia sobre el resto de España, la formulación de esa pregunta requiriese algún acuerdo de voluntades entre el Gobierno catalán y el Gobierno de España, o esas cosas.

¿Por qué era bueno eso a mi juicio? Porque, en primer lugar, me parece que es bueno que los pueblos tengan la posibilidad de expresar su voluntad. En segundo lugar, porque es bueno llamar a las cosas por su nombre. Y un referéndum es un referéndum, y no una consulta, ni una encuesta. Como he dicho el otro día, las encuestas se dirigen al hombre, miembro de la sociedad civil; el referéndum se dirige al ciudadano, miembro de un pueblo, que es una unidad de voluntad que se manifiesta a través de la mayoría. Y porque, además, si no se hubiera centrado la discusión, absurdamente, en el procedimiento, se podría haber entrado a discutir sobre la sustancia, que es lo importante: qué significa la independencia, qué es lo que cabe esperar de ella, etcétera.

Doble referéndum. ¿Por qué? Si lo de que el referéndum tenga un carácter meramente consultivo es una forma de hablar. Cuando un órgano representativo consulta 
al pueblo cuya representación ostenta, es muy difícil que ese órgano representativo se aparte de la opinión expresada por ese pueblo. Entonces, si el pueblo de Cataluña se manifiesta, manifiesta su voluntad de independencia, pues el Parlamento de Cataluña tendrá que presentar, hacer una proposición de reforma constitucional para asegurar la independencia. Y esa reforma constitucional habrá que tramitarse de acuerdo con su procedimiento y puede terminar, eventualmente, en un referéndum, en el que todo el pueblo español habrá de manifestarse.

Eso en lo que toca a esa cuestión. Después, vamos a la cuestión inicial en la medida en que la recuerdo -que a lo mejor sí-.

La Constitución. Yo estuve presente en la elaboración de la Constitución, estuve muy presente. Estaba en contacto, por supuesto, con los llamados padres de la Constitución, y no solo con ellos. Por ejemplo, una de las personas con las que yo más contacto tuve en aquella época fue con Javier Arzallus, con quien hice -creo- una buena amistad. Y viví junto a él momentos transcendentales, como por ejemplo el momento en el que se llevó a cabo la última discusión entre Javier y Fernando Abril, porque me pidieron los dos que se hiciera en mi despacho, y en mi presencia, de manera que eso lo viví bastante bien.

Los derechos históricos. Mire usted, la noción de derechos históricos tiene un componente indudable, clarísimo, que es que se forma parte de esa realidad, de esa realidad política. El País Vasco no tiene derechos históricos frente a Letonia, Estonia o Lituania, o frente al Gran Ducado de Varsovia. Tiene derechos históricos frente a una comunidad (...), una comunidad política, de la que ha sido parte, y por eso son derechos históricos. De manera que la idea de la nación de naciones se refleja -a mi juicio-, justamente, en la noción de derechos históricos.

La definición de cuáles sean esos derechos históricos. Bueno, usted sabe muchísimo mejor que yo, muchísimo mejor que yo, cuál ha sido la historia de los fueros vascos. Una historia realmente sorprendente, porque los fueros vascos son suprimidos y vuelven a remontar una y otra vez.

El primero que crea -me parece- una comisión de estudios para estudiar los abusos de los territorios forales fue Godoy. Eso después desaparece, con la caída de Godoy. La Constitución del 12, las cosas quedan parece que suprimidas, pero no suprimidas, Fernando VIl lo (...) y Fernando VII vuelve a crear una comisión de (...). Pues bueno, la historia, qué le voy a decir a usted que no sepa.

La cláusula famosa de la actualización de los derechos históricos en el marco de la Constitución. Bueno, yo creo que eso se puede hacer, pero no es una vía muy prometedora, a mi juicio, porque identificar cuáles son los derechos históricos en el pasado -en marcos absolutamente distintos, en marcos, por ejemplo, en donde no existía la soberanía nacional y el pueblo vasco no formaba parte por eso del ente soberano, que estaba compuesto por súbditos de su majestad católica, etcétera- no es fácil. 
Yo creo que es más razonable y más prometedor, desde el punto de vista de la eficacia, utilizar la noción de derechos históricos como una base definitoria de la propia personalidad, como una base definitoria de la singularidad del pueblo vasco en el seno de España, pero no como un receptáculo de donde convenga extraer las cosas que nos convienen, porque eso se va a prestar siempre a mucha discusión y desmitificación, etcétera, etcétera. De manera que yo creo que la noción de derecho histórico tiene validez como afirmación de singularidad, pero no, repito, como receptáculo de derechos concretos, eso es más difícil de detectar.

A partir de ahí, naturalmente, cuáles pueden ser esas aspiraciones del País Vasco. Como decía Reif , si esas aspiraciones (...), o como crea Reif, sinceramente, esas aspiraciones son una, la aspiración la independencia, a mi juicio, eso desborda la noción misma de derechos históricos, porque la noción de derechos históricos no implica la independencia, más bien la niega, y no podría incorporarse por esa vía.

De ahí para abajo todo es posible, todo es posible en el marco en el que nos movemos actualmente. Ya he explicado que, para mí, ese marco es el del estado social de derecho y que se impone pues limitaciones y abre posibilidades, por supuesto.

No sé si he contestado mucho. Yo ya te he dicho lo que (...). Estoy intentando no ser brillante ni ser agudo, ni ser erudito, sino, fundamentalmente, ser sincero a los (...). Siempre, y mucho más a mi edad, lo que tiene que decir uno es lo que de verdad piensa.

LANTALDEAREN KOORDINATZAILEAK:

¿Los portavoces van a querer abrir un segundo turno?

MANEIRO LABAYEN jaunak:

Sí, de manera muy breve, sobre todo para agradecer su presencia en esta ponencia y quizás para hacerle una pregunta sobre una cuestión que estaba usted tratando ahora con el señor Egibar.

Quería preguntarle si considera usted que, en fin, Andalucía, Galicia o Castilla pueden tener también derechos históricos, o por qué los derechos históricos que pudieran tener otras comunidades o regiones españolas pues no fueron incorporados a la Constitución española. Qué diferencia hay, por lo tanto, en relación al País Vasco.

Gracias.

RUBIO LLORENTE jaunak:

Bueno, vamos a ver, la cláusula constitucional dice: "Los derechos históricos de los territorios forales". Y parece obvio que ni Andalucía ni Extremadura ni etcétera han tenido fueros. 
Y como siempre sucede en política, hay una contaminación de los conceptos como en el País Vasco, además de derechos históricos hay nacionalismo, entonces como esas otras comunidades autónomas, algunas de ellas, no podían invocar derechos históricos, han invocado nacionalidad propia. Y Andalucía se ha convertido en nacionalidad y (...) cosa que, a mi juicio, hasta cierto (...) incluso grotesca, porque no (...) su parte de la legislación española y de (...), pero, vamos, la razón de que no se le pueda reconocer derechos históricos es que los derechos históricos que se reconocen son los de los territorios forales.

El problema grave es el de Cataluña, como es obvio. Cataluña tiene derecho de bien foral, pero no se ha considerado derecho foral, territorio foral porque no tiene fuero, y, sin embargo, Cataluña, pues tiene una personalidad políticamente diferenciada como la del País Vasco. Y no lo podemos negar y hay que encontrar encaje para eso. El encaje a través de los hechos diferenciales, pues da de sí lo que da de sí, y cuando todavía me visitaba el expresidente Pujol de tiempo en tiempo, todavía, este año, antes de que empezara la hecatombe, me dijo: "El fet diferencial de Cataluña, es Cataluña”. Bueno, pues en cierto sentido, eso es verdad, el fet diferencial de Cataluña no es la lengua, es Cataluña, que tiene pues una conciencia de singularidad política.

Hasta qué punto esa conciencia de singularidad política tiene un apoyo social extenso. Yo tengo muchas dudas de que los muchos extremeños y andaluces y murcianos y castellanos que viven en Cataluña se sientan arrebatados por el entusiasmo, por la tradición, por casanovas, por las resistencias frente al Borbón, o por la defensa de una lengua que no tienen como lengua materna.

De hecho, de hecho, si nos ponemos a hablar de hechos, la deriva independentista del presidente Mas o del Govern de la Generalitat se inicia cuando, en una entrevista con Rajoy, le niega lo que él llamaba pacto económico, que era una cosa que se parecía bastante al sistema de concierto o de convenio. Y la defensa que se ha hecho de, que se está haciendo de la independencia, allí es una defensa basada en razones básicamente económicas. Es que los catalanes, si no tienen que compartir su riqueza con España, van a vivir mejor y van a tener más recursos para atender a sus propias necesidades.

Probablemente es así, aunque no seguramente así. Que hace unos años, una urbanización muy rica, en Madrid, llamada la Moraleja, pretendió segregarse del municipio del que formaba parte, Alcobendas, para tener unos servicios sociales mejores. Pues, evidentemente, hubiera sido así. Éticamente hubo muchos -entre los que yo me encuentro- que eso nos pareció deleznable.

Y uno de los problemas que hay ahora en esa vía es en las llamadas no incorporated areas en los Estados Unidos, que son urbanizaciones de lujo que no forman parte de municipio alguno. Y que ahora se va a imitar en Madrid. El Gobierno municipal de Madrid -por supuesto, sin que se entere el PSOE de ello- está siguiendo esa vía con 
la creación de los barrios prime, que son unos barrios en los que los servicios sociales están financiados en parte por los propios vecinos, con los cuales se consigue que haya barrios con servicios sociales mejores que otros. Pero bueno, eso es aparte. Eso es aparte.

Ahora bien, el que se mejoren todos porque se reserva una mayor riqueza para repartir entre todos, no es tan seguro. Porque el aumento de la tarta -para decirlo en términos comunes- no asegura que la tarta se divida por igual entre todos. Y como bien sabemos, y se ha hecho famoso con el libro de Piketty y con el libro de -a mi juicio espléndido-, de Wolfgang Streeck, Gekaufte Zeit. La riqueza de los ricos, el incremento gigantesco de la riqueza de los ricos, en nuestro tiempo, corre parejo con el decrecimiento, igualmente espantoso, de la pobreza de los pobres. De manera que el incremento de la tarta no asegura que mejore la situación de todos, sino solo que se crea las posibilidades que eso sea, pero también las posibilidades de que la riqueza de los ricos siga, crezca más que la pobreza de los pobres.

Otra cuestión, de la cual, por supuesto, los partidos de izquierda de este país no parecen haberse enterado. Pero, qué le vamos a hacer, así son las cosas.

Bueno, y hasta aquí hemos llegado, o ¿hay más preguntas?

LANTALDEAREN ANTOLATZAILEAK:

El señor Prieto tiene la palabra.

PRIETO SAN VICENTE jaunak:

Sí, yo le quería, simplemente aclarar o, en fin, apostillar a lo que usted ha dicho.

Que yo estoy de acuerdo con usted en que el Estado tiene una crisis institucional. Estoy de acuerdo con que la vía de solución no son las reformas estatutarias, sino la reforma constitucional. Estoy de acuerdo con que hay que llevar las competencias de las comunidades autónomas a la Constitución para evitar conflictos. Estoy de acuerdo con que tiene que haber un federalismo simétrico en cuanto a la igualdad jurídica y, probablemente, asimétrico en cuanto a otros conceptos que pueden ser diferenciales. Estoy de acuerdo con la defensa del estado social que ha hecho. También sobre la definición del derecho a decidir.

En fin, en general, su exposición me ha parecido muy coincidente con cosas que pienso y que sabe que pensamos en el socialismo.

Donde me ha llamado más la atención es en la crítica o en las referencias que ha hecho a la parte del Concierto y del Cupo. Y lo que pretendía, con algunos datos que yo le he dado, sobre todo, es saber por qué llega a esa reflexión, que de alguna forma ya lo ha explicado. Esta era la razón de que la intervención la hubiera hecho en ese sentido. 
RUBIO LLORENTE jaunak:

No tenía usted porque dar explicaciones. Está todo claro y meridiano.

LANTALDEAREN ANTOLATZAILEAK:

El señor Arraiz no va a participar.

RUBIO LLORENTE jaunak:

LANTALDEAREN ANTOLATZAILEAK:

Pues, el señor Iturrate, de Nacionalistas Vascos, tiene (...)

ITURRATE IBARRA jaunak:

Sí. Dos preguntas muy breves al hilo de la exposición inicial.

Usted se ha declarado partidario del sistema federal asimétrico de una manera (...) resumiendo. Y apuntaba que las nacionalidades -las nacionalidades o las entidades nacionales o (...)- deben tener un lugar en el proceso constituyente. Si podría concretar un poco más cómo, cómo se puede realizar ese lugar específico, esa participación en el proceso constituyente. Y si ese mismo principio cree usted que debería regir también, luego, en el control de constitucionalidad o en el Tribunal Constitucional. Si las nacionalidades, los entes nacionales también deberían de tener un lugar en la conformación o en la toma de decisiones del órgano encargado del control de constitucionalidad.

RUBIO LLORENTE jaunak:

Como usted comprenderá, le agradezco las preguntas, como usted comprenderá, yo no tengo una respuesta fácil para esas preguntas. Y no puedo más que apuntar ideas que habría que discutir y matizar mucho.

Respecto a lo primero, hombre, cabe imaginar, en teoría, que una reforma constitucional, para el futuro -porque ahora tenemos lo que tenemos-, que una reforma constitucional para el futuro, primero, empieza por una reforma constitucional en el presente.

Una reforma constitucional en el presente requeriría -en mi opinión- que se negociara, no solo con los partidos que por sí solos disponen de mayoría suficiente en las Cortes, sino que se negociara también con los partidos nacionalistas, moderados, radicales, o lo que fuera, para llegar a acuerdos que - por lo menos- no fueran considerados como casus belli por ellos, que es una manera de definir el consenso. 
El consenso no significó nunca, ni en el 78, que se estaba de acuerdo en todo, sino que al menos se consideraba que los acuerdos no eran tan hirientes que determinasen la hostilidad absoluta. Eso en cuanto a la tramitación previa del (...).

Para el futuro. Hombre, se podría imaginar un procedimiento de reforma en la que, además de la aprobación por el Congreso de los Diputados -donde todos los diputados son iguales-, se requiriese una aprobación en el Senado, y que en el Senado, el voto de las distintas partes componentes del Estado español se ponderase, de manera que el voto de las nacionalidades históricas -terminología que se puede utilizar- no resultase inevitablemente aplastado por el voto del resto de las comunidades autónomas, de manera que el voto se hiciera ponderando no solo el número de habitantes, sino también la condición, digamos, nacional, ¿no?

Eso no aseguraría, por supuesto, que no se pudiera hacer una reforma si el País Vasco se oponía a ella. Pero, sí podría hacer muy difícil o imposible, una reforma a la que se opusiera el País Vasco, Navarra y Cataluña. Pongo por caso (...). Repito, que esto habría que verlo con más detalle, estoy sugiriendo ideas, solo ideas generales.

Incluso, en el supuesto del referéndum, pues podría hacerse el recuento de los votos populares, de manera que tuvieran algún peso específico los votos populares depositados en estas circunscripciones.

Son, no sé si son ideas o son simplemente ocurrencias. Tengo la esperanza de que sean ideas y que se puedan pulimentar más reflexionando sobre ellas, pero es lo que le puedo decir a usted ahora. Más allá de ello no me atrevo a llegar.

Creo que es posible. Creo que es posible. Por supuesto, por ejemplo, en el caso de los Estados Unidos, como es bien sabido, la reforma de la Constitución, las llamadas enmiendas, requieren que el voto favorable de tres cuartas partes de los estados, son tres cuartas partes de los estados.

Bueno, en una ponderación de ese género, ya cada estado tiene un peso propio. Lo cual me lleva a alguna cuestión que planteé al principio. El mapa político de España. No creo que eso sea fácilmente modificable. Pero, yo, para decir la verdad, con el mapa político de España me siento incómodo. El actual. No veo con claridad la necesidad de que España cuente con 17 comunidades autónomas distintas. No veo (...). Vamos, sé cuales son los motivos que llevaron a su creación, pero no la razón de ser de comunidades como la Rioja o Cantabria, o Murcia. Y para decirlo todo, y tirando piedras contra mi tejado, no veo muy claro por qué Castilla la Nueva y Extremadura forman dos comunidades autónomas distintas. Somos la misma cosa. Somos lo que se llamaba en el viejo régimen, las grandes provincias. Etcétera, etcétera. Es decir, que sería, España, a mi juicio, sería mucho más clara, y así, quizá, más fácilmente gobernable, si el mapa político de España se redujera a seis o siete u ocho comunidades. Pero bueno, eso es lo que (...). Y eso haría, también más fácil, ponderar el peso de las distintas comunidades en la reforma constitucional a nivel constituyente. 
Estoy, como ven ustedes, como un viejo ilusorio. Bueno, cada uno es lo que es. Y me voy a (...)

Muchísimas gracias a todos, señores, por su paciencia y su cortesía.

\section{LANTALDEAREN ANTOLATZAILEAK:}

Muchas gracias a usted por sus aportaciones. Y con esto ya damos por finalizada la sesión de hoy.

(...)

Eguerdiko ordu bata eta berrogeita hamaseian amaitu da bilkura. 